\title{
SEISMIC MATERIAL PROPERTIES OF REINFORCED CONCRETE AND STEEL CASING COMPOSITE CONCRETE IN ELEVATED PILE-GROUP FOUNDATION
}

\author{
Mi Zhou \\ Key Laboratory for Old Bridge Detection and Reinforcement Technology of the Ministry of \\ Transportation, Chang'an University, Xi'an, Shaanxi, China \\ National Engineering and Research Center for Highways in Mountain Area, Chongqing, China \\ Wancheng Yuan \\ State Key Laboratory for Disaster Reduction in Civil Engineering, Tongji University, Shanghai \\ 200092, China \\ Yue Zhang \\ School of Construction and Civil Engineering Xi'an University of Science and Technology, Xi'an, China
}

\begin{abstract}
The paper focuses on the material mechanics properties of reinforced concrete and steel casing composite concrete under pseudo-static loads and their application in structure. Although elevated pile-group foundation is widely used in bridge, port and ocean engineering, the seismic performance of this type of foundation still need further study. Four scale-specimens of the elevated pile-group foundation were manufactured by these two kinds of concrete and seismic performance characteristic of each specimen were compared. Meanwhile, the special soil box was designed and built to consider soil-pile-superstructure interaction. According to the test result, the peak strength of strengthening specimens is about 1.77 times of the others and the ultimate displacement is 1.66 times of the RC specimens. Additionally, the dissipated hysteric energy capability of strengthening specimens is more than 2.15 times of the others as the equivalent viscous damping ratio is reduced by 50\%. The pinching effect of first two specimens is more obvious than latter two specimens and the hysteretic loops of reinforced specimens are more plumpness. The pseudo-static tests also provided the data to quantitatively assessment the positive effect of steel casing composite concrete in aseismatic design of bridge.
\end{abstract}

Keywords: pseudo-static tests, material properties, reinforced concrete, steel composite concrete

\section{INTRODUCTION}

The elevated pile-group foundation is widely used in large span or long bridges. Although the foundation form has advantages of strong adaptability, little project cost and short construction period, the disaster investigation shows it still is the vulnerable component in bridge under earthquake. The seismic performance of this type of foundation has not been studied carefully up to now (Zhou Mi and Yuan Wancheng, 2010 [10]; Yuan Wan-cheng and Jun Yang, 2007 [8]). Many bridges have been built in recent years with this type of foundation in China, but almost no existing design guidelines and design codes dealt with the design and computation of large-scale elevated pile-group foundations under dynamic loading. This paper studied the material mechanics properties of reinforced concrete and steel casing composite concrete under pseudo-static loads. Meanwhile, the seismic behaviors of the elevated pile-group foundation specimens which were cast by these two kinds of materials were compared and analyzed.

Experimental activities on 4 scale-models of the elevated pile-group foundation belonging to a real bridge were studied in the paper. The tests consist of cyclically imposed displacement to 4 specimens, performed in the state key laboratory for disaster reduction in civil engineering of Tongji University. Two specimens named as ST-specimen which were strengthened by steel protective pipe at each pile top to compare with original reinforced concrete specimen named as RC-specimen. In the paper, pseudo-static testing and damage mechanisms of two kinds of specimens were summarized. 


\section{PSEUDO-STATIC MODEL TESTS}

The tests consist of cyclically imposed displacement to 4 specimens, performed in the electro-hydraulic servo loading system of Tongji University. Two specimens were steel composite concrete structures and others were reinforced concrete structures which were respectively named as ST-specimen and RC-specimen. The pile-group foundation model was composed by 9 piles. Because the actuator is located at the bottom of loading equipment, models were required to be installed in inversion method. So a combined type soil-box was designed in the paper. When dynamic factors were ignored the soil around pile could be considered as a series of linear or nonlinear springs. The soil-box combined flexural rigidity of steel sheet and axial stiffness of pull rod to simulate the soil-pile interaction. In Fig.1, elevation photos of pile-group foundation model were shown and the special soil box details were expressed in Fig.2. Six rows of steel springs were built for each pile to consider soil-pile-superstructure interaction. (a)

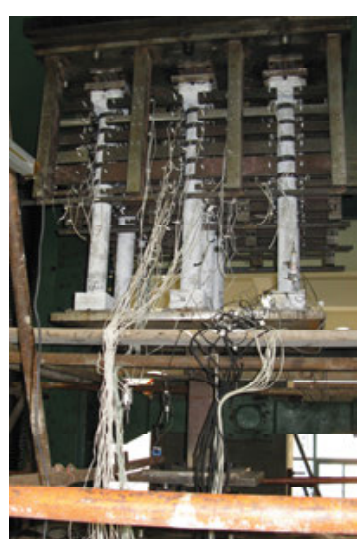

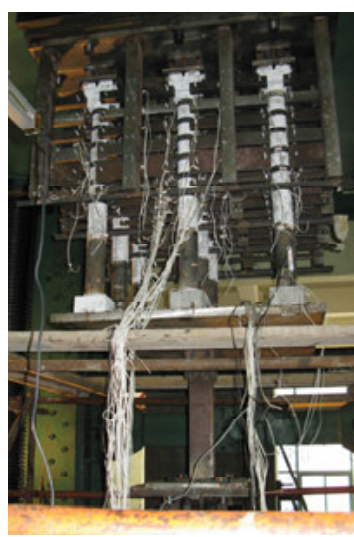

(b)
Fig. 1. The elevation photos of pile group foundation models: (a) RC-specimen (b) ST-specimen

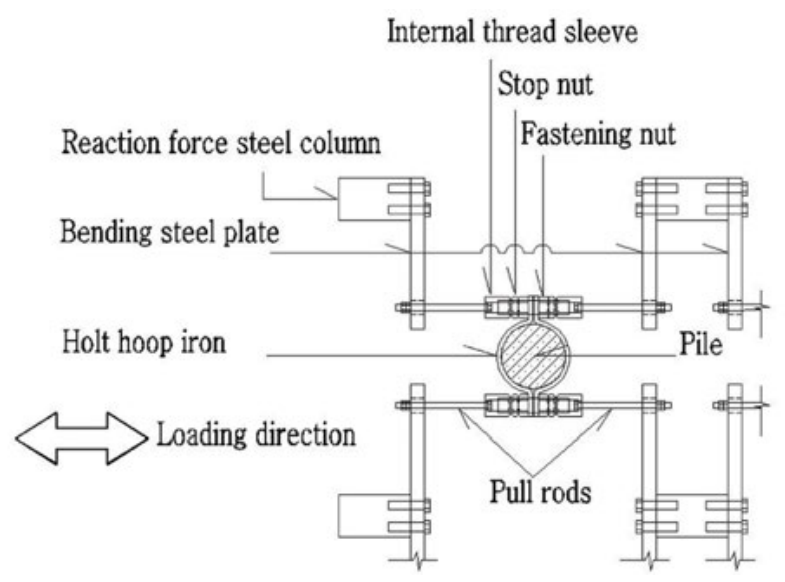

(a)

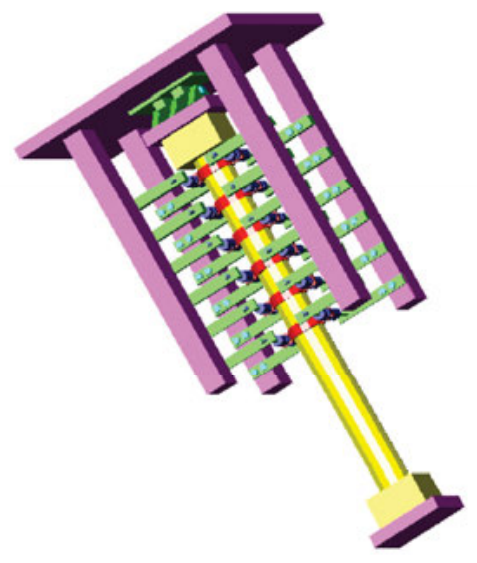

(b)

Fig. 2. The special soil box detail: (a) The layout plan of soil box (b) The $3 D$ schematic plot of the soil box

The amplitude of the cycles is variable from $2 \mathrm{~mm}$ to 80 $\mathrm{mm}$. In each load amplitude, three cycles of displacements have been imposed. The frequency of the applied signal is equal to $0.02 \mathrm{~Hz}$ in order to realize a quasi-static test [6]. The dead load acting on the scaled pier is equal to $75 \mathrm{kN}$. Piles were poured by $\mathrm{C} 30$ concrete. Correspondingly pile cap and pier were accurately machined by Q235 steel. Design parameters of scaled models were listed in Table 1.

\section{LOAD-DISPLACEMENT HYSTERETIC PROPERTY OF SPECIMENS}

After data analysis, the hysteretic properties are very similar from elevated pile cap system to single component. Hysteretic curves forming process of all specimens are nearly same. The area of hysteretic circle which is consisted of loadingand-unloading curves is very small before concrete crack, resembling a sharp-shuttle (Fig.3).

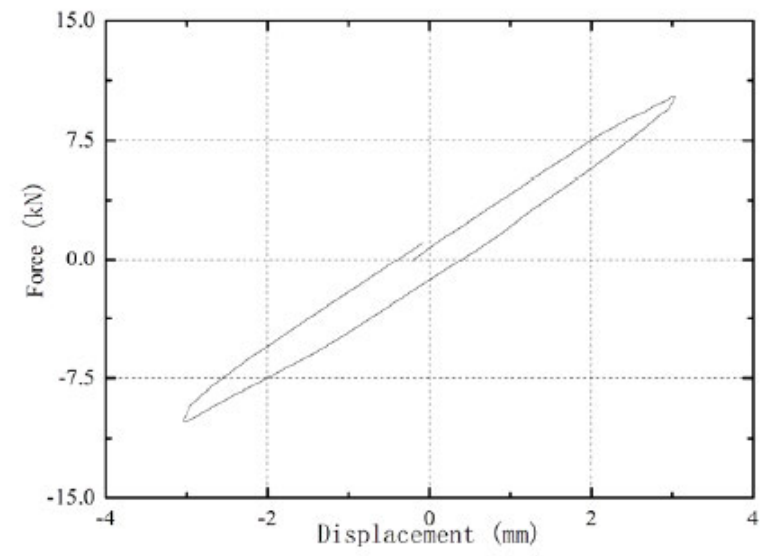

Fig. 3. Hysteretic circle in elastic stage $(u<1)$ Fig. 4. Hysteretic circle in yield stage $(u>1)$

While deformation is getting larger, horizontal cracks in concrete surface begin to appear in succession, and damaged degree of specimen increase gradually. The shape of hysteretic 
Tab. 1. Design parameters of models

\begin{tabular}{|c|c|c|c|c|c|c|c|c|c|}
\hline \multirow{2}{*}{$\begin{array}{c}\text { Specimen } \\
\text { number }\end{array}$} & Scale & $\begin{array}{c}\text { Pile } \\
\text { diameter }\end{array}$ & $\begin{array}{c}\text { Pile } \\
\text { space }\end{array}$ & $\begin{array}{c}\text { Free } \\
\text { segment }\end{array}$ & $\begin{array}{c}\text { Main } \\
\text { reinforcement } \\
\text { ratio }\end{array}$ & $\begin{array}{c}\text { Hoop } \\
\text { reinforcement } \\
\text { ratio }\end{array}$ & $\begin{array}{c}\text { Steel casing } \\
\text { thickness/ } \\
\text { length }\end{array}$ & $\begin{array}{c}\text { Pier } \\
\text { height }\end{array}$ & $\begin{array}{c}\text { Vertical force } \\
\text { at the top } \\
\text { of pier }\end{array}$ \\
\cline { 2 - 11 } & & {$[\mathrm{cm}]$} & {$[\mathrm{cm}]$} & {$[\mathrm{cm}]$} & $(\%)$ & $(\%)$ & {$[\mathrm{mm}]$} & {$[\mathrm{cm}]$} & {$[\mathrm{kN}]$} \\
\hline RC-1,2 & $1: 20$ & 9.0 & 44.5 & 49.0 & 0.871 & 0.379 & none & 72.0 & 75.0 \\
\hline ST-3,4 & $1: 20$ & 9.0 & 44.5 & 49.0 & 0.871 & 0.379 & $1.0 / 400$ & 72.0 & 75.0 \\
\hline
\end{tabular}

circle inchmeal achieves transition from a narrow line shape to a relatively full shuttle shape (Fig.4), which shows the typical hysteretic property of bending component, besides, loading and unloading rigidity decrease gradually with the increase of deformation.

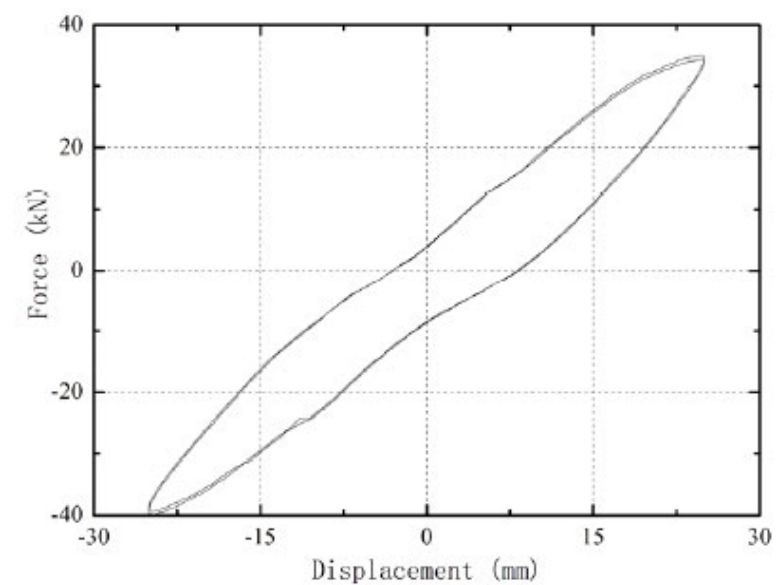

Fig. 4. Hysteretic circle in yield stage $(u>1)$

When the deformation continues increasing, damage becomes more severe, width of horizontal crack is gradual extending, along with which, there are turning up of a small quantity of oblique and vertical cracks. Meanwhile, the hysteretic circle begins to presents certain shrinkage, but there's no such effect on the third and the forth specimen.

In destruction stage, hysteretic circles of RC specimens have the gradual transition from spindles to bows, and there is pinch phenomenon in the middle, which indicates that relatively slide between reinforcing bar and concrete is obvious (Fig.5), as well as $P-\Delta$ effect has strongly influence on the two specimens [9]. Rigidity variation of the two specimens in the mass is stable, there are typical bending characteristics in damage zone, before failure displacement mainly produces horizontal crack, and oblique ones don't appear. There are vertical cracks on outside concrete due to vertical compression when failure is drawing near. Because the RC specimen is bending failure, in addition to reinforcement ratio is moderate, there are some warning signs before the last limit state. When the displacement on pier top is up to $35 \mathrm{~mm}$, concrete on pile head splits apart and rubs off constantly under cyclic loading, and the rigidity of the whole system begins to degenerate more quickly. When reached the limits of displacement, degeneration of rigidity and strength grows. By the agency of steel pipe, initial rigidity of the third and fourth specimen is greater than the first two specimens. Their hysteretic circles are spindle shape in initial stage. Because the steel tube on pile head has strong confinement effect to core concrete, concrete expansion is restricted and the growth of the cracks in core concrete is also arrested. Moreover, bond-slip between steel and concrete is reduced. The hysteretic circles of the latter two specimens are much full compared with the former two's, and they transform from spindle shape to Z-shape gradually in destruction stage (Fig.6), which indicates that the failure model is shear-slip construction [6]. The reason is that there is an abrupt change of bearing capacity of pile at the end of the steel pipe, which's the just position the second plastic hinge forms. The shear failure of the latter two specimens was caused by the lacking of shear resistance in the position where the cross section is changing.

a)

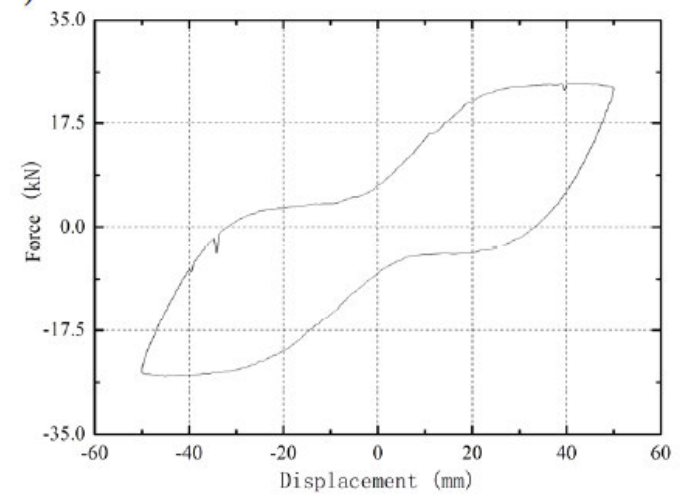

b)

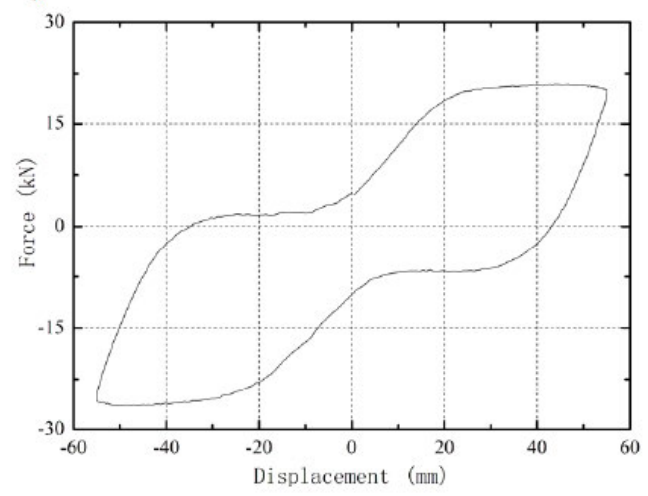

Fig. 5. Hysteretic circle of the RC specimen in destruction: (a) RC-1 specimen (b) RC-2 specimen 
a)

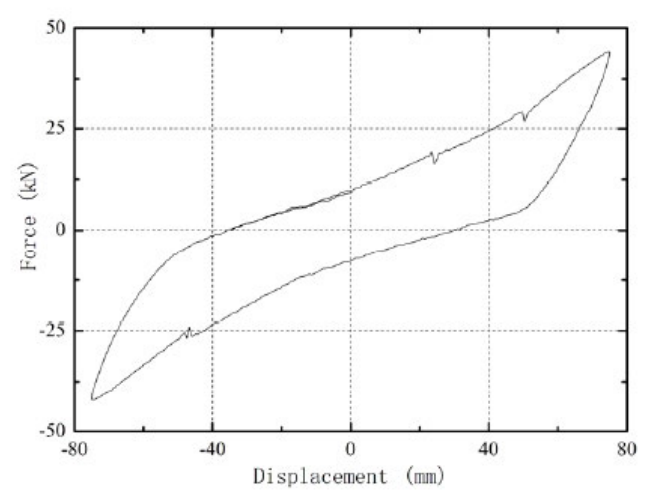

b)

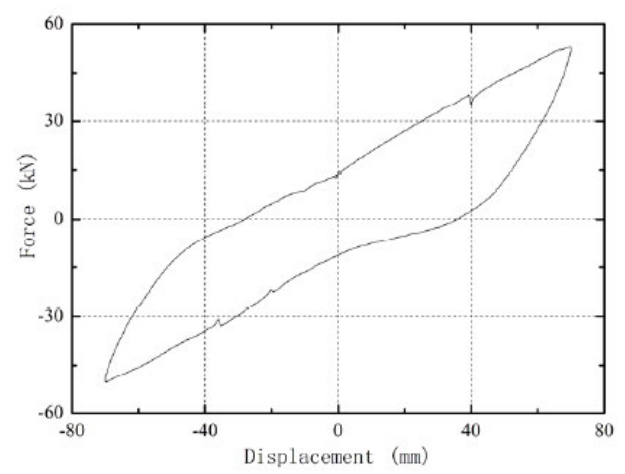

Fig. 6. Hysteretic circle of the ST specimen in destruction: (a) ST-1 specimen (b) ST-2 specimen

In the test, the damages of side piles always occurred prior to middle piles in pile-group foundation. The force-displacement hysteretic curves of side piles are given in Fig.7. The single pile force-displacement hysteretic curves reflect anti-seismic property of components. From comparing the figures, the pinch effect of hysteretic curve is more obvious in reinforced concrete piles. Furthermore, if cyclic displacement imposed at the top of the pier and the base shear force were one to one corresponded with, measured force - displacement cyclic response of specimens are shown in Fig.8. Fig.8 shows that the peak strength of ST specimens is about 1.77 times of the others and the ultimate displacement of ST-specimens is 1.66 times of the RC-specimens. It indicates that the bearing capacity of the foundation increased obviously by strengthening the plastic hinge zone of piles with steel tubes.

a)

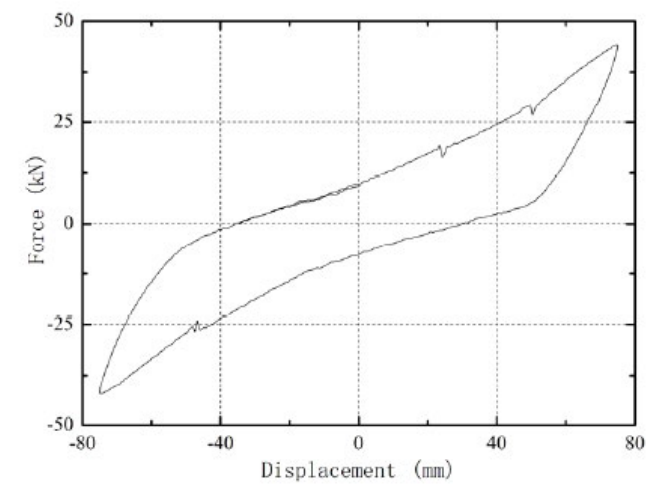

b)

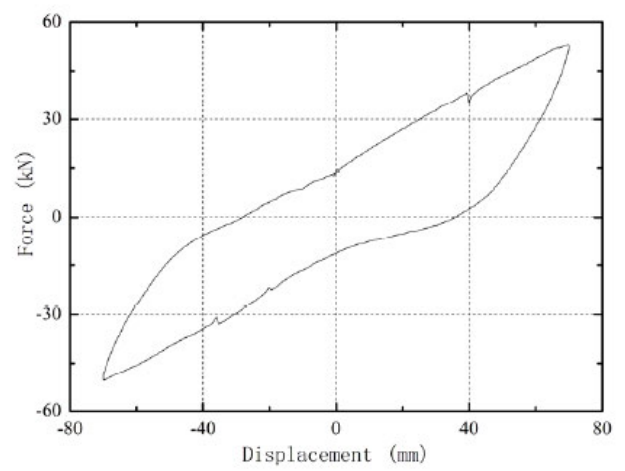

Fig. 7. Force-displacement curve of side pile: (a) RC-1 specimen (b) ST-1 specimen

\section{SKELETON CURVES OF SPECIMENS}

Restoring force characteristics of elevated pile-cap system can be fully expressed by skeleton curves. Measured skeleton curves of specimens were shown in Fig.9, which can be drawn by FEMA356 method. Some laws can be found from

Tab. 2. Characteristics of skeleton curve

\begin{tabular}{|c|c|c|c|c|c|c|c|c|c|c|c|c|}
\hline \multirow{3}{*}{$\begin{array}{l}\text { Items } \\
\text { Specimen } \\
\text { number }\end{array}$} & \multicolumn{6}{|c|}{ Positive loading } & \multicolumn{6}{|c|}{ Reversed loading } \\
\hline & $\begin{array}{c}\text { Yield } \\
\text { displacement }\end{array}$ & $\begin{array}{c}\text { Peak } \\
\text { displacement }\end{array}$ & $\begin{array}{c}\text { Ultimate } \\
\text { displacement }\end{array}$ & $\begin{array}{c}\text { Yield } \\
\text { strength }\end{array}$ & $\begin{array}{c}\text { Peak } \\
\text { strength }\end{array}$ & $\begin{array}{l}\text { Ultimate } \\
\text { strength }\end{array}$ & $\begin{array}{c}\text { Yield } \\
\text { displacement }\end{array}$ & $\begin{array}{c}\text { Peak } \\
\text { displacemen }\end{array}$ & $\begin{array}{c}\text { Ultimate } \\
\text { displacement }\end{array}$ & Yield & $\begin{array}{c}\text { Peak } \\
\text { strength }\end{array}$ & Ultimate \\
\hline & \multicolumn{3}{|c|}{$/ \mathrm{mm}$} & & $\angle \mathrm{kN}$ & & \multicolumn{3}{|c|}{$/ \mathrm{mm}$} & \multicolumn{3}{|c|}{$/ \mathrm{kN}$} \\
\hline Specimen 1 & 10.952 & 23.921 & 41.093 & 27.624 & 35.949 & 30.556 & -10.150 & -26.031 & -41.239 & -27.322 & -37.714 & -32.057 \\
\hline Specimen 2 & 12.119 & 24.328 & 42.597 & 28.211 & 36.321 & 30.872 & -11.114 & -28.047 & -44.265 & -29.238 & -40.942 & -34.801 \\
\hline Specimen 3 & 18.086 & 49.669 & 67.362 & 40.603 & 64.226 & 54.591 & -18.373 & -49.548 & -68.734 & $\mid-35.720$ & -61.247 & -52.060 \\
\hline Specimen 4 & 20.004 & 49.628 & 70.208 & 45.601 & 68.512 & 58.235 & -19.933 & -49.385 & -68.892 & -43.856 & -64.870 & $\mid-55.140$ \\
\hline
\end{tabular}




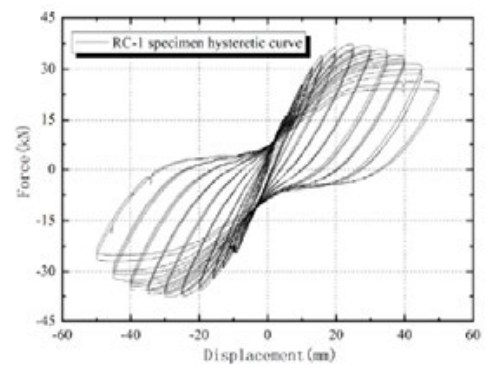

(a)

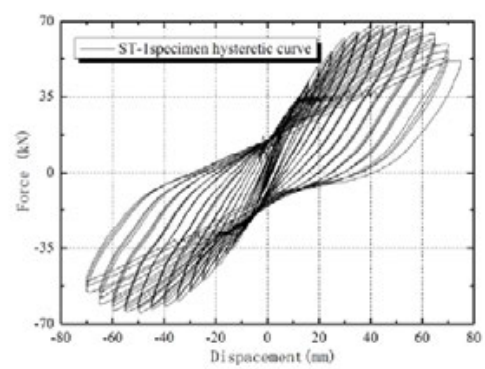

(c)

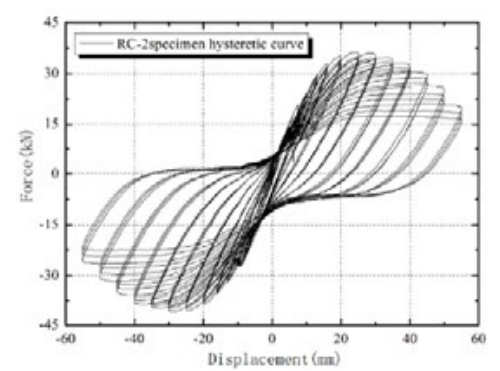

(b)

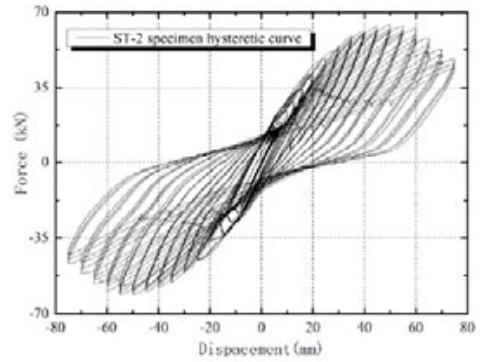

(d)

Fig. 8. Measured force - displacement cyclic response of specimens: (a) RC-1 specimen (b) RC-2 specimen (c) ST-1 specimen (d) ST-2 specimen

summarizing the specimens' skeleton curves. All measured skeleton curves can be simplified to three linear models. There is a long strength steady section in skeleton curves of the RC specimens, which shows that the plastic deformation ability of the first two specimens is obvious. Post-yield stiffness of the latter two specimens is $5 \%$ to $20 \%$ higher than the former two's. Greater post-yield stiffness helps to decrease residual displacement and maintain stability of the structure which is advantage for aseismatic design of bridge [4]. For the reason of strengthen function by steel pipe, horizontal resistance and ultimate deformation capacity of elevated pile caps of the latter two specimens improved greatly: peak tensile strength has been raised by $77 \% \sim 88 \%$, while ultimate displacement has been raised by $55 \% \sim 63 \%$. For all specimens, skeleton curves of the first three cyclic loading are relatively stable, nearly overlapping in early stage, but there are obvious deviation between every cyclic loading after yield stage.

Referring to reinforced concrete hysteretic model, broken-lined models are commonly used for simpleness and convenience. Skeleton curves of elevated pile caps can be idealized to 3 -line sketch curve model [3,7], and the statistics data are shown in Tab. 2.

\section{DISPLACEMENT DUCTILITY OF SPECIMENS}

Displacement ductility coefficient is an important index which reflects ductility anti-seismic ability of structure. The greatest displacement ductility coefficients of the four specimens are given in Table 3. In the table, the coefficient $u_{m i}$ can be given as:

$$
u_{m i}=\frac{\Delta_{u}}{\Delta_{y i}}
$$

where $\Delta_{u}$ is the ultimate displacement in skeleton curves of specimen and $\Delta_{y i}$ is the first yield displacement in skeleton curves of specimen. The coefficient $u_{m e}$ can be can be described as following equation:

$$
u_{m e}=\frac{\Delta_{u}}{\Delta_{y e}}
$$

where $\Delta_{u}$ is the ultimate displacement in skeleton curves

Tab. 3. Statistics of displacement ductility ratio

\begin{tabular}{c|c|c|c|c|c|c}
\hline \multirow{2}{*}{ Items } & \multicolumn{2}{c}{$\begin{array}{c}\Delta_{y e} \\
\text { /mm }\end{array}$} & \multicolumn{2}{c}{$u_{m i}$} & \\
$\begin{array}{c}\text { Specimen } \\
\text { number }\end{array}$ & $\begin{array}{c}\text { Positive } \\
\text { loading }\end{array}$ & $\begin{array}{c}\text { Reversed } \\
\text { loading }\end{array}$ & $\begin{array}{c}\text { Positive } \\
\text { loading }\end{array}$ & $\begin{array}{c}\text { Reversed } \\
\text { loading }\end{array}$ & $\begin{array}{c}\text { Positive } \\
\text { loading }\end{array}$ & $\begin{array}{c}\text { Reversed } \\
\text { loading }\end{array}$ \\
\cline { 2 - 7 } & 14.590 & -14.072 & 3.752 & 4.063 & 2.816 & 2.931 \\
\hline Specimen 1 & 15.135 & -16.355 & 3.515 & 3.983 & 2.814 & 2.706 \\
\hline Specimen 2 & 26.336 & -30.053 & 3.724 & 3.741 & 2.558 & 2.287 \\
\hline Specimen 3 & 29.834 & -28.445 & 3.510 & 3.456 & 2.353 & 2.416 \\
\hline Specimen 4 & & & & & &
\end{tabular}




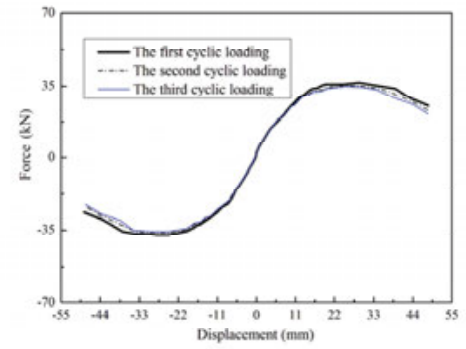

(a)

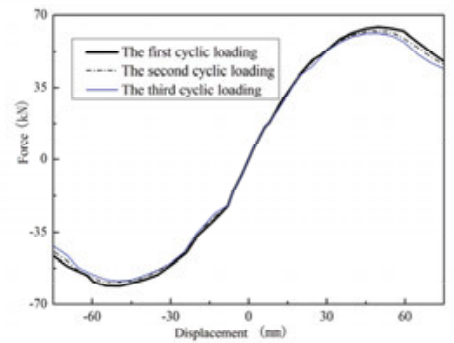

(c)

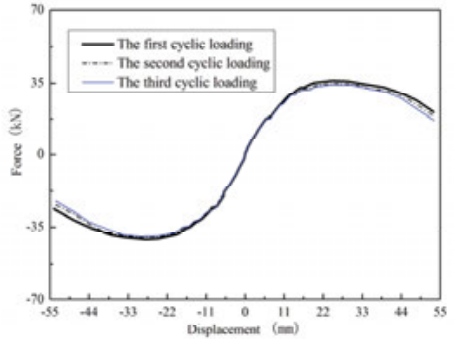

(b)

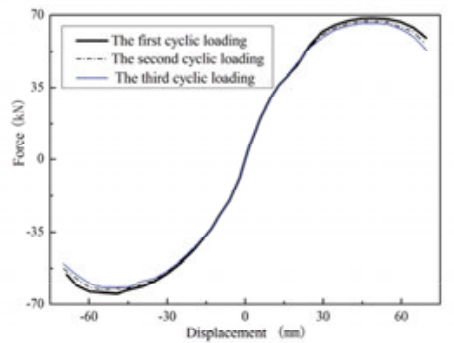

(d)

Fig. 9. Measured skeleton curve of specimens: (a) RC-1 specimen (b) RC-2 specimen (c) ST-1 specimen (d) ST-2 specimen

of specimen and $\Delta_{y e}$ is the equivalent yield displacement in skeleton curves of specimen. The equivalent yield displacement can be calculated by energy balance method (Priestley, 1998[5]; Caltrans SDC, 2001[1]).

The displacement ductility coefficients of the former two specimens are greater than the latter twos', that's mainly because elevated pile cap's yield displacement of RC pile is $50 \%$ less than ST specimens. Although the ultimate displacement of the latter two specimens improved highly, depending on minor yield displacement, the displacement ductility capacity of RC specimens is nearly as same as ST specimens. Accumulated displacement ductility coefficient $N_{\Delta}$ can be obtained according to Formula 3:

$$
N_{\Delta}=\sum_{i=1}^{n} \frac{\Delta_{m i}}{\Delta_{y i}}
$$

In the equation, $\Delta_{m i}$ is the mean value of the largest displacement with both positive and negative loading directions when cyclic loading number is i; $\Delta_{y i}$ is the first yield displacement; $n$ is the number of laps for cyclic loading.

If define 'drift ratio' as displacement on the pier top under horizontal load divided by the height between pier top and scour line and define 'ultimate destruction' as the horizontal resistance decreases to $85 \%$ of the maximum resistance, then ultimate destruction state arrives while drift ratio reach to $4.6 \%$ for ST specimens; but the drift ratio is only $2.8 \%$ when adopting RC pile foundation when ultimate destruction state arrives. Accumulated displacement ductility ratio and ultimate drift ratio of all specimens are listed in Table 4.
Tab. 4. Statistics of accumulated displacement ductility ratio and drift ratio

\begin{tabular}{|c|c|c|c|}
\hline Items & $\begin{array}{l}\text { Accumulated } \\
\text { displacement }\end{array}$ & \multicolumn{2}{|c|}{$\begin{array}{l}\text { Ultimate drift ratio } \\
\%\end{array}$} \\
\hline Specimens & $N_{\Delta}$ & $\begin{array}{c}\text { Positive } \\
\text { direction }\end{array}$ & $\begin{array}{l}\text { Negative } \\
\text { direction }\end{array}$ \\
\hline specimen 1 & 71.128 & 2.758 & 2.768 \\
\hline specimen 2 & 88.869 & 2.859 & 2.971 \\
\hline specimen 3 & 104.336 & 4.521 & 4.613 \\
\hline specimen 4 & 94.332 & 4.712 & 4.624 \\
\hline
\end{tabular}

Many researchers have pointed out that the conclusion will be limiting when a single displacement ductility index is used to evaluate the ductility of the structure [2]. From the collection of seismic disaster investigation and experimental research, anti-seismic capability of structure is not only relevant to the greatest ductility displacement, but also depending on plasticity energy consumption capacity. Energy-dissipating capacity of two kinds of specimens will be discussed below.

\section{ENERGY-DISSIPATING CAPACITY OF SPECIMENS}

Energy-dissipating capacity as well as ductility ability, is regarded as an important index of structural anti-seismic performance. The energy conservative relation which is expressed by Eqn. 4 is always true if collapse of the bridge structure does not appear.

$$
E_{K}(t)+E_{D}(t)+E_{H}(t)+E_{E}(t)=E_{t}(t)
$$


where $E_{K}(t)$ and $E_{E}(t)$ are respectively representing for the kinetic energy and elastic deformation energy of the structure; $E_{D}(t)$ and $E_{H}(t)$ are respectively representing for the damping dissipation energy and hysteretic dissipation energy of structure; $E_{t}(t)$ is the total energy of the earthquake input.

Cumulative hysteretic dissipation energy $E_{A D}$ is defined as the total hysteretic dissipation energy of the specimens under reciprocating load from the beginning to destroy, namely the sum of every hysteretic loop's area:

$$
E_{A D}=\sum_{i=1}^{n} \Delta W_{i}
$$

where $E_{A D}$ is specimen's cumulative hysteretic dissipation energy; $n$ is loading number of turns; $\Delta W_{i}$ is representing for the hysteretic loops area of the i level load. The value of $E_{A D}$ for each specimen is shown in Table 5 . The variation trend of dissipation energy with loading level is shown in Fig.10. The test results show that the elevated pile cap's structure cumulative energy-dissipating capacity get improvement after using steel pipe in RC pile. Comparing with RC specimen, the energy dissipation ability of ST specimen improved about two times.

Tab. 5. Cumulative hysteretic dissipation energy of each specimen

\begin{tabular}{|c|c|c|c|c|}
\hline $\begin{array}{c}\text { Specimen } \\
\text { number }\end{array}$ & Specimen 1 & Specimen 2 & Specimen 3 & Specimen 4 \\
\hline$E_{A D /(\mathrm{kN} \cdot \mathrm{mm})}$ & 25416.437 & 34763.099 & 72213.229 & 74813.938 \\
\hline
\end{tabular}

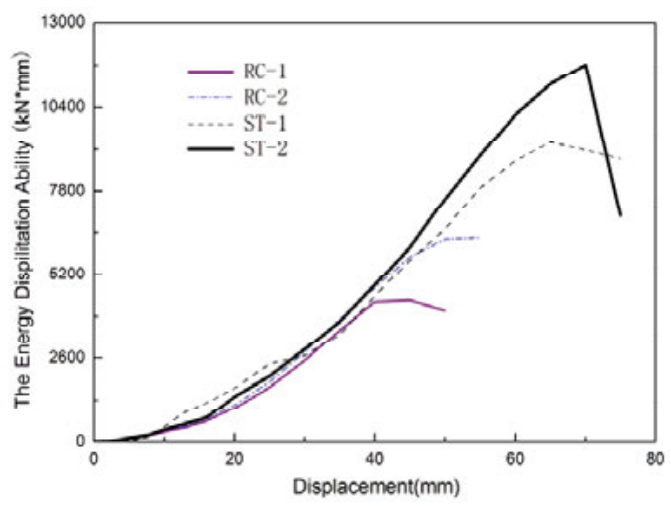

Fig. 10. The dissipated hysteretic energy capability of specimen

Equivalent viscous damping ratio is another significant coefficient in pseudo-static test. It can link structure damping to viscous damping model. Equivalent viscous damping coefficient is defined as follow:

$$
\xi_{e q, h}=\frac{1}{2 \pi} \frac{E_{H}(t)}{E_{E}(t)}
$$

where $\xi_{e q, h}$ is equivalent viscous damping ratio; $E_{H}(t)$ and $E(t)$ are respectively representing for the hysteretic dissipation energy and elastic deformation energy of the structure.

Fig. 11 shows the equivalent viscous damping ratio $\xi_{\text {eq }, h}$ increase with the rise of displacement ductility coefficient $u_{i}$. It shows that with the concrete crack or the steel bar yield, the hysteretic energy dissipation of specimens increase. Before the main reinforcement yield, equivalent viscous damping ratio of the first specimen and the second specimen changes between 0.05 and 0.07 ; for the third specimen and the fourth specimen, it changes from 0.04 to 0.08 . After the steel bar yield, $\xi_{e q, h}$ of the first and second specimen increase observably; when the specimens destroy, the value of $\xi_{e q, h}$ can reach 0.258 and 0.283 respectively; the equivalent figures of the third and the fourth specimen are 0.136 and 0.164 , which also explain that damage degree of pile-group is restrained after steel casing composite concrete is used.

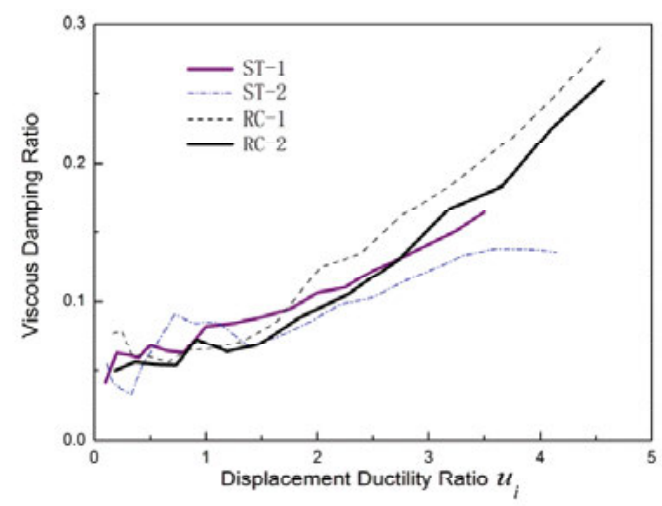

Fig. 11. The equivalent viscous damping ratio of specimen

\section{CONCLUSIONS}

The paper deals with experimental activity on four scalespecimens of elevated pile-group foundation belonging to a real bridge. Two of them are reinforced concrete structure, others are steel composite structure. The experimental results indicated that the seismic capacity of the foundation increased obviously by using steel casing composite concrete in damageable zone of piles. This measure can effectively improve the bending strength of RC pile, delay crushing and failure of concrete, delay the yielding of longitudinal bars in plastic hinge regions and avoid fracture failure of longitudinal bars. According to test, the peak strength of strengthening specimens is about 1.77 times of the others and the ultimate displacement is 1.66 times of the original models. Additionally, the dissipated hysteric energy capability of strengthening specimens is more than 2.15 times of the others as the equivalent viscous damping ratio is reduced by $50 \%$. Finally, other relevant phenomena and failure mechanisms of the elevated pile-group foundation were summarized. 


\section{ACKNOWLEDGEMENTS}

This research is supported by Ministry of Transport of China (the project No. is 2015319812010), the Fund of National Engineering and Research Center for Highways in Mountain Area (the project No. is gsgzj-2012-07), China Postdoctoral Science Foundation under Grant No. 2012M511959.The paper is also funded by China Scholarship Council.

\section{REFERENCES}

1. California Department of Transportation (CALTRANS): 'Seismic Design Criteria, Version 1.2', Sacramento, California:, published December 2001.

2. Fan Li-chu and Zhuo Wei-dong: 'Ductility anti-earthquake design of bridge', People Traffic Press Beijing, China, 2001.

3. Guo Zi-xiong,LuXi-lin: 'Study on frame column restoring force with high axial compression ratio model test', China Civil Engineering Journal,2004,37:32-38

4. Macrae, G.A. and Kawashima, K.: 'Post-Earthquake Residual Displacement of Bilinear Oscillators', Earthquake Engineering \& Structural Dynamics, 1997, 26, 701-716.

5. Priestley M.J.N. : 'Brief Comments on Elastic Flexibility of Reinforced Concrete Frames and Significance to Seismic Design', Bulletin of the New Zealand National Society for Earthquake Engineering, 1998,31:246-259

6. R. Giannini, F. Paolacci and E. Sibilio: 'Experimental study on the cyclic response of an existing RC bridge pier', Proceedings of the 14th world conference on earthquake engineering, China, September 2008, Beijing.

7. Takeda T, Sozen M A, Nielson N N.: 'Reinforced concrete response to simulated earthquakes', Journal of Structural Division,1970, 96 (STI2) :2557-2572

8. Yuan Wan-cheng and Jun Yang: 'Lateral load pattern study of pushover analysis for elevated pile foundation system of bridges', Journal of Tongji University, 2008, 36, 1468-1472.

9. Zhou Mi: 'Experimental and Theoretical Studies on Seismic Performance of Elevated Pile Cap Bridge', $\mathrm{PhD}$ thesis, Tongji University, Shanghai, China, 2008, 82-102.

10. Zhou Mi and Yuan Wan-cheng: 'Parameter sensitivity analysis of equivalent anchorage length for elevated pile caps', Journal of Chang'an University, 2010, 30, 47-52.

\section{CONTACT WITH THE AUTHORS}

Mi Zhou

Key Laboratory for Old Bridge Detection and Reinforcement Technology of the Ministry of Transportation

Chang'an University, Xi'an, Shaanxi

National Engineering and Research Center for Highways in Mountain Area, Chongqing tel.: +862982334868, fax: +862982334434 email: zhoumi@chd.edu.cn CHINA 